\title{
Enlargement of the Sylvian aqueduct: a sequel of head injuries
}

\author{
FRANÇOIS C. BOLLER, ${ }^{1}$ MARTIN L. ALBERT, MARJORIE LEMAY, \\ AND ANDREW KERTESZ ${ }^{2}$ \\ From the Neurology and Radiology Services, Boston Veterans Administration Hospital, \\ Boston University School of Medicine, and the Department of Radiology, \\ Harvard Medical School, Boston, Mass., U.S.A.
}

SUMMARY A review of pneumoencephalography and clinical data in a large group of patients has shown that severe head injury may be followed by a consistent clinical-radiological syndrome. A prolonged period of unconsciousness is a characteristic initial feature of this syndrome. Clinically there is ataxia and dysarthria and, often, abnormal movements and oculomotor dysfunction. The characteristic radiological feature is an enlargement of the aqueduct of Sylvius. The clinical picture, together with the enlargement of the aqueduct, suggests that loss of neuronal and axonal substance in the midbrain is the probable pathology.

In 1947, Kremer, Russell, and Smyth described a 'midbrain syndrome' after severe head injury in nine patients. The dominant clinical signs were dysarthria, oculomotor and pupillary disturbances, ataxia, and tremor. The limb ataxia was usually more pronounced on one side, and on that side 'pyramidal' signs were also present. The two cases which had pneumoencephalography (PEG) performed showed a marked enlargement of the aqueduct of Sylvius.

This post-traumatic midbrain syndrome is rarely mentioned in modern literature on head injuries. Similarly, little attention is paid, in the course of PEG interpretations, to the size of the aqueduct.

The present study was undertaken to assess the clinical history and neurological findings in a group of patients in whom PEG had disclosed an abnormally wide aqueduct.

\section{METHODS AND RESULTS}

The radiological findings were reviewed in 350 consecutive pneumoencephalographic studies at the Boston Veterans Administration Hospital. Cases were selected for review who showed enlargement of the Sylvian aqueduct ( $3 \mathrm{~mm}$ or more in diameter) but whose 4th ventricles were normal or only slightly enlarged. All cases with intracranial space occupying

\footnotetext{
1 Reprint requests to Dr. Boller, Boston Veterans Administration Hospital, 150 S. Huntington Ave., Boston, Mass. 02130, U.S.A.

2 Now at University of Western Ontario, London, Ontario.
}

lesions were excluded. Note was also made in the selected cases of the size of the lateral, third, and 4 th ventricles. The clinical records of these patients were reviewed for pertinent clinical history and neurological findings.

Fifteen cases with PEG evidence of enlargement of the aqueduct without striking enlargement of the 4th ventricle were found. The Table presents a summary of clinical and neuroradiological data of these patients. Figure 1 shows an example of the enlarged aqueduct and 4th ventricle in a typical case (patient R.D.)

PATIENTS WITH HISTORY OF HEAD INJURY

HISTORY Thirteen of the 15 patients had a history of significant head injury. Their age ranged from 22 to 60 years with a mean of 38 years. In all except three patients the injuries occurred between four and 20 months before the pneumoencephalogram. In all of these patients, symptoms developed after the head injury. Two of the three whose accident had occurred 18 and 25 years before the study reported symptoms since the time of the injury. The third patient had head trauma 20 years before PEG. Ataxia, dysarthria, and abnormal movements were present when he was first seen five years before the study but the precise time of their onset is unknown. Nine patients had been involved in automobile accidents, two had fallen while working on a scaffold, one (D.J.) had fallen on his head at the age of 6 years and one (C.J.), an ex-boxer, had been knocked out several times in addition to a head injury sustained in a car accident 20 years before 


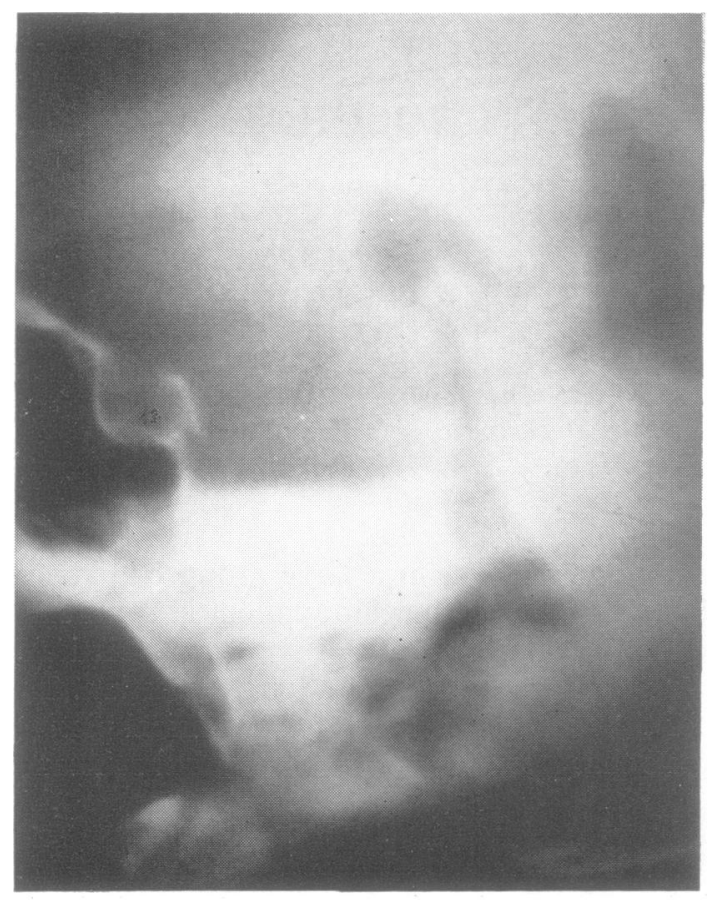

(a)

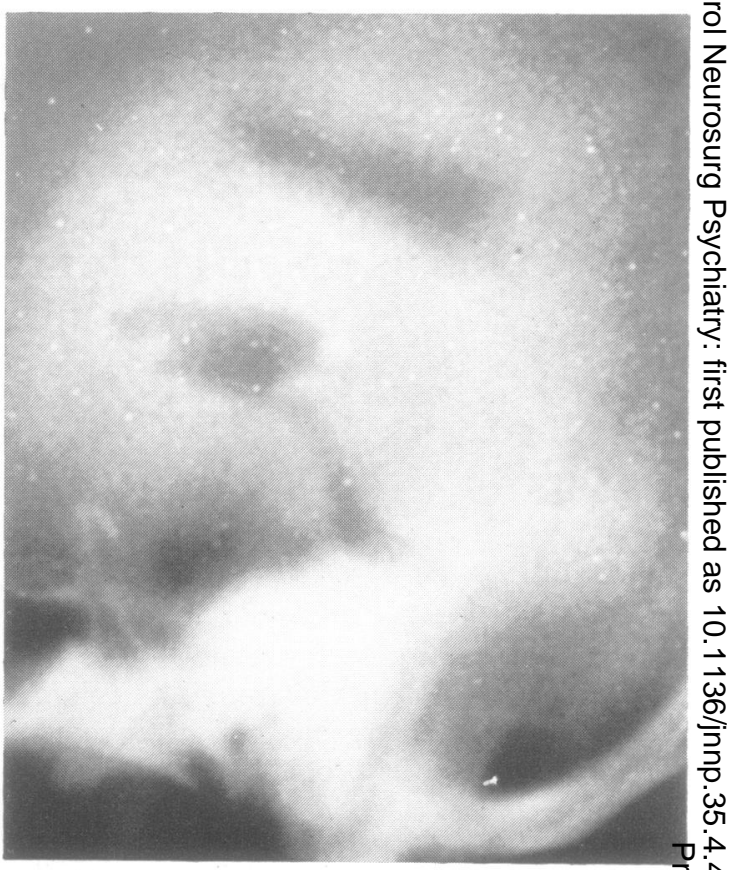

(b)

TABLE

SUMMARY OF RADIOLOGICAL AND CLINICAL DATA IN 15 PATIENTS WITH ENLARGED AQUEDUCT*

\begin{tabular}{|c|c|c|c|c|c|c|c|c|c|c|c|c|c|c|}
\hline & 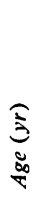 & 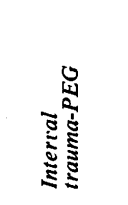 & 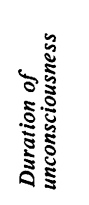 & 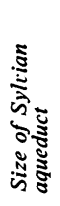 & 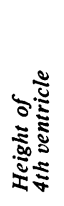 & 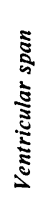 & 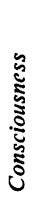 & 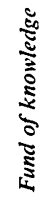 & . & $\frac{\pi}{\vdots}$ & 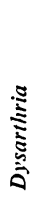 & 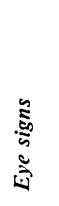 & 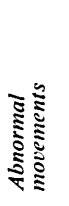 & Other signs or symptoms \\
\hline B.F. & 49 & $4 \frac{1}{2}$ months & 3 days & 3.5 & 15 & 40 & $\downarrow$ & NT & NT & No & No & No & No & Left hemiparesis \\
\hline B.M. & 60 & 8 months & Hours & 6 & 17 & 62 & 0 & $\downarrow$ & $\downarrow$ & No & No & No & No & Right hemiparesis \\
\hline C.M. & 49 & 13 months & Hours & 3.5 & 13 & 45 & 0 & 0 & 0 & Yes & Yes & Yes & No & Loud speech, 7th, 8th, RA \\
\hline C.J. & 54 & 20 years & Days & 4 & 18 & 59 & 0 & $i$ & $\downarrow$ & Yes & Yes & No & Yes & Left facial, postural tremor \\
\hline C.G. & 26 & $5 \frac{1}{2}$ months & $\begin{array}{l}\text { Many } \\
\text { days }\end{array}$ & 3 & 18 & 42 & 0 & $\downarrow$ & $\downarrow$ & Yes & Yes & No & Yes & Head titubation, RA \\
\hline D.J. & 31 & 25 years & & 7 & 23 & 43 & 0 & $\downarrow$ & & Yes & Yes & No & No & \\
\hline $\begin{array}{l}\text { G.J. } \\
\text { M.P. }\end{array}$ & $\begin{array}{l}38 \\
22\end{array}$ & $\begin{array}{l}11 \text { months } \\
20 \text { months }\end{array}$ & $\begin{array}{l}3 \text { days } \\
4 \text { days }\end{array}$ & $\begin{array}{l}3.5 \\
6\end{array}$ & $\begin{array}{l}15 \\
20\end{array}$ & $\begin{array}{l}47 \\
46\end{array}$ & $\begin{array}{l}\mathbf{0} \\
\mathbf{0}\end{array}$ & $\begin{array}{l}\downarrow \\
0\end{array}$ & $\begin{array}{l}\downarrow \\
0\end{array}$ & $\begin{array}{l}\text { Yes } \\
\text { No }\end{array}$ & $\begin{array}{l}\text { Yes } \\
\text { No }\end{array}$ & $\begin{array}{l}\text { No } \\
\text { No }\end{array}$ & $\begin{array}{l}\text { Yes } \\
\text { No }\end{array}$ & $\begin{array}{l}\text { Left hemiparesis } \\
\text { Post-traumatic syndrome; Had R } \\
\text { PTA }\end{array}$ \\
\hline M.R. & 32 & 6 months & Weeks & 5 & 19 & 67 & $\downarrow$ & NT & NT & No & No & No & No & Akinetic mute \\
\hline M.C. & 23 & $4 \frac{1}{2}$ months & Weeks & 3 & 14 & 41 & 0 & $\downarrow$ & $\downarrow$ & Yes & Yes & Yes & No & Aphasia, right hemiparesis \\
\hline N.J. & 42 & 6 months & Days & 3 & 19 & 57 & 0 & NT & NT & Yes & Yes & Yes & Yes & Right hemiparesis \\
\hline O.J. & 42 & 18 years & Hours & 5 & 23 & 62 & 0 & 0 & 0 & Yes & Yes & Yes & Yes & Resting tremor \\
\hline R.D. & 25 & $4 \frac{1}{2}$ months & Days & 4 & 14 & 59 & $\downarrow$ & NT & NT & Yes & Yes & Yes & Yes & $\begin{array}{l}\text { Head bobbing, RA, R internucle } \\
\text { ophthalmoplegia }\end{array}$ \\
\hline S.T. & 67 & - & - & 3.5 & 11 & 57 & 0 & $\downarrow$ & $\downarrow$ & Yes & No & No & Yes & RHH, dystonia, apraxia \\
\hline A.R. & 54 & - & - & 3.5 & 19 & 45 & 0 & 0 & $\mathbf{0}$ & No & No & No & No & Left hemiparesis \\
\hline
\end{tabular}

* All but the last two (S.T. and A.R.) had sustained a head injury.

Radiological measurements are given in millimetres. $0=$ normal. NT= not testable. $\downarrow=$ decreased. RA= Retrograde amnesia. PTA= post traumatic amnesia. $\mathbf{R H H}=$ right homonymous hemianopsia. 
PEG. A definite history of impaired consciousness was elicited in all cases; in nine of the cases coma lasted 48 hours or more. Five had sustained skull fracture. Two of the patients with skull fracture and an additional patient underwent craniotomy for evacuation of subdural and epidural haematomas. Seven patients had a history of heavy alcohol intake and four had post-traumatic seizures.

PEG FINDINGS In all cases the aqueduct was enlarged throughout its length, ranging from 3 to $7 \mathrm{~mm}$ in width. The normal width of the aqueduct is between 1 and $2 \mathrm{~mm}$ (Sutton, 1950; Robertson, 1957).

The height of the fourth ventricle in the lateral view (distance from the floor to the fastigium) was less than $21 \mathrm{~mm}$ except in two patients (D.J. and O.J.) in which it was $23 \mathrm{~mm}$; both Sutton (1950) and Robertson (1957) give the figures of 13 to $21 \mathrm{~mm}$ as normal range for this measurement.

The width of the third ventricle was normal (less than $9 \mathrm{~mm}$ ) in two cases; in two instances it was not adequately outlined. It was enlarged up to $19 \mathrm{~mm}$ in the other cases.

In all cases the lateral ventricles were enlarged. The width of right and left lateral ventricles (ventricular span) in all patients was above the $40 \mathrm{~mm}$ figure given by Nielsen, Petersen, Thygesen, and Willanger (1966) as upper limit of normal.

Clinical FINDINGS AT TIME OF PEG Nine of the 13 patients with head injury showed dysarthria, unsteadiness of gait, ataxia, and dysmetria of limbs. Five of these patients showed ocular signs (3rd nerve weakness in one case, right internuclear ophthalmoplegia in another case, and nystagmus in three cases); six of these patients also had abnormal movements (head titubation in four cases and bilateral resting tremor in two).

One patient (M.R.) showed akinetic mutism and PEG findings were characteristic of those of normal pressure hydrocephalus (Benson, LeMay, Patten, and Rubens, 1970). His clinical condition improved after ventricular atrial shunt.

Among the other three patients, two had abnormal mental status and a hemiparesis and one (M.P.) had a negative neurological examination. This last patient had a post-traumatic syndrome (Glossary of Head Injuries, Caveness and Walker, 1966) and PEG was carried out to rule out a space occupying lesion as source of his excruciating headaches for which he had attempted suicide.

Most patients were alert at the time of the PEG examination; three (including M.R. with akinetic mutism) had impaired consciousness. Fund of knowledge and memory were normal in only three of the 13 cases. Most affected were recent memory functions, including in several cases the circumstances of and events preceding the accident. Two of the three patients with normal memory function gave a history of retrograde amnesia.

PATIENTS WITHOUT HISTORY OF HEAD INJURY

Only two patients fell into this category. One (S.T.) had a progressive onset of dementia, apraxia, right homonymous hemianopsia, and right hemiparesis with markedly dystonic posture of the right upper limb; there were also gait disturbances, ataxia of limbs, and bilateral resting tremor. He had sustained a head injury two months before PEG but the trauma occurred several months after the onset of most of the symptoms. Necropsy performed on this patient has shown neuropathological findings compatible with Pick's disease. At the level of the mesencephalon there was loss of myelin in the white matter; there was also loss of neurones and depigmentation of the substantia nigra. The second patient (A.R.), a diabetic, had gradual onset of spastic hemiparesis and some weakness of the muscles innervated by the lower branch of the VII nerve and by the XII nerve on the left. Other cranial nerves and mental status were entirely normal. PEG was performed under the clinical impression that the patient could have a slowly growing space occupying lesion. The lateral ventricles, third ventricle, and aqueduct were enlarged. The right lateral ventricle was larger than the left. He was discharged with a tentative diagnosis of infarction in the right middle cerebral artery territory. This patient has since died of pulmonary neoplasia without new neurological deficits. Permission for necropsy was not granted.

\section{DISCUSSION}

In the present study $85 \%$ of subjects with enlargement of the aqueduct of Sylvius without widening of the 4 th ventricle (13 out of 15 cases) had a history of severe head injury before the development of symptoms. On this basis we propose that aqueductal enlargement may often be a neurological sequel in patients who survive head injury.

These clinical-radiological observations receive theoretical support from studies of brain pathology after head trauma. Strich (1969) has reported degeneration of nerve fibres in the cerebral hemispheres and brain-stem, especially in the midline, after head injury, a finding first described in 1899 by Rosenblath. Strich believes that this degeneration is a consequence of tearing or stretching of nerve fibres due to mechanical forces acting at the moment of the accident (Strich 1956, 1961). Kremer et al. (1947) postulated the possibility of haemorrhagic lesions in the mesencephalon itself, which might be produced either by uncal herniation of the 
cerebral hemispheres or, as suggested by Courville (1945), by bruising of the mesencephalon against the tentorium, or by a rotational strain of the hemispheres pulling on the brain-stem. Three recent pathological studies (Crompton, Teare, and Bowen, 1966; Oppenheimer, 1968; Crompton, 1971) have shown both axonal shearing with demyelination and haemorrhagic or necrotic lesions in the midbrain of patients who died following head injury.

The neurological signs and symptoms in the present group of subjects appeared to be related to brain-stem pathology, although the clinical pattern which emerged was not uniform. Ataxia and dysarthria, often with a scanning quality, were present in nine cases, some of whom also showed ocular disturbances and abnormal movements. These cases, therefore, would seem to fit into the 'midbrain syndrome' described by Kremer et al. (1947). They also have features in common with the cases described by Kertesz and Tasker (1966) who showed involuntary movements associated with midbrain lesions in four patients. It must be recognized, however, that the same signs could be attributed to lesions in other areas than the mesencephalon-namely, the cerebellum, basal ganglia, and lower brainstem. Incidentally three of our patients with nystagmus, intention tremor, and scanning speech represent a further illustration that Charcot's triad is by no means confined to multiple sclerosis.

One of our patients showed akinetic mutism which is a recognized clinical correlate of midbrain lesions. Once again, however, the same clinical state may also be seen with lesions elsewhere, particularly in the thalamus and frontothalamic connections (Segarra, 1970).

The prominence of the post-traumatic impairment of consciousness seen in nine of these 13 cases is significant. There is controversy concerning the localization of the lesions responsible for loss of consciousness in concussion and other traumatic syndromes. In a recent monograph Mealey (1968) has summarized the theoretical positions regarding brain-stem alteration in cases with loss of consciousness. The present findings favour the hypothesis that dysfunction of brain-stem structures is associated with post-traumatic disturbances of consciousness (Ward, 1966).

As for the two cases with no history of head injury, the first showed neuropathological evidence of Pick's disease. The enlargement of the aqueduct was probably related to botho demyelination of the white matter of the mes- $Z$ encephalon and the loss of neurones in the $=$ substantia nigra. The second patient had now brain-stem sign, and we have no obvious ex-⿳亠二口犬 planation for the PEG evidence of aqueductal 0 enlargement. This case may parallel those in whom large ventricles or other anatomical abnormalities represent an accidental finding in $\vec{z}$ patients who are neurologically normal (see, $\stackrel{\Rightarrow}{\Rightarrow}$ for example, the case reported by Nathan and $\stackrel{?}{?}$ Smith, 1950).

Finally, the infrequent reporting of enlarge- $\frac{\bar{O}}{\bar{C}}$ ment of the Sylvian aqueduct and the 'midbrain $\vec{\nabla}$ syndrome' sometimes associated with it after $\bigcirc$ head injuries and other lesions deserves comment. It is conceivable that they are not very $\overrightarrow{0}$ often searched for and therefore are perhaps $\overrightarrow{\vec{\omega}}$ overlooked. It is also possible that mesencephalic $\stackrel{\omega}{\sigma}$ lesions after head injuries are often lethal and $\overline{5}$ that therefore the margin is very small between a? symptomless survival and death of the patient. of The authors wish to thank Dr. Jose M. Segarra wi has kindly supplied the neuropathological data om one of our patients. We also wish to thank D. D. Frank Benson for his valuable advice on tre manuscript.

\section{REFERENCES}

Benson, D. F., LeMay, M., Patten, D. H., and Rubens, A. ¥. N (1970). Diagnosis of normal-pressure hydrocephalus. New England Journal of Medicine, 283, 609-615.

Courville, C. B. (1945). Effects of closed cranial injuries on the midbrain and upper pons. In Trauma of the Central Nervous System. Association for Research in Nervous and Mental Disease, 24, 131-150.

Crompton, M. R. (1971). Brainstem lesions due to closed head injury. Lancet, 1, 669-673.

Crompton, M. R., Teare, R. D., and Bowen, D. A. L. (1966). $\overline{\mathrm{O}}$ Prolonged coma after head injury. Lancet, 2, 938-940.

Caveness, W. F., and Walker, A. E. (1966). (Eds.). Head injury glossary. In Head Injury. Conference Proceedings, $\overline{0}$ pp. 571-576. Lippincott: Philadelphia.

Kertesz, A., and Tasker, R. R. (1966). Involuntary movement associated with midbrain lesion in man. Transactions of the $\frac{\overrightarrow{0}}{0}$ American Neurological Association, 1, 270-272.

Kremer, M., Russell, W. R., and Smyth, G. E. (1947). A midbrain syndrome following head injury. Journal of Neurology, Neurosurgery, and Psychiatry, 10, 49-60.

Mealey, J. (1968). Pediatric Head Injuries. Thomas: Spring- 3 field, Ill.

Nathan, P. W., and Smith, M. C. (1950). Normal mentality associated with maldeveloped 'rhinencephalon'. Journal $D$ of Neurology, Neurosurgery, and Psychiatry, 13, 191-197. 으․

Nielsen, R., Petersen, O., Thygesen, P., and Willanger, R. (1966). Encephalographic ventricular atrophy. Acta o Radiologica (Diagnosis), 4, 240-256.

Oppenheimer, D. R. (1968). Microscopic lesions in the brain $\mathrm{N}$ following head injury. Journal of Neurology, Neurosurgery, $\omega$ and Psychiatry, 31, 299-306.

Robertson, E. G. (1957). Pneumoencephalography. Blackwell: Oxford. 
Rosenblath, W. (1899). Ueber einen bemerkenswerthen Fall von Hirnerschütterung. Deutsche Archiv für klinische Medizin, 64, 406-427.

Segarra, J. M. (1970). Cerebral vascular disease and behavior. I. The syndrome of the mesencephalic artery (basilar artery bifurcation). Archices of Neurology, 22, 408-418.

Strich, S. J. (1956). Diffuse degeneration of the cerebral white matter in severe dementia following head injury. Journal of Neurology, Neurosurgery, and Psychiatry, 19, 163-185.

Strich, S. J. (1961). Shearing of nerve fibres as a cause of brain damage due to head injury. A pathological study of twenty cases. Lancet, 2, 443-448.

Strich, S. J. (1969). The pathology of brain damage due to blunt head injuries. In The Late Effects of Head Injury. Edited by A. E. Walker, W. F. Caveness, and M. Critchley, pp. 501-526. Thomas: Springfield, Ill.

Sutton, D. (1950). The radiological assessment of the normal aqueduct and 4th ventricle. British Journal of Radiology, 23, 208-218.

Ward, A. A. (1966). The physiology of concussion. In Head Injury. Conference Proceedings, pp. 203-208. Edited by W. F. Caveness and A. E. Walker. Lippincott: Philadelphia. 